\title{
Does strategic alignment matter when SMEs adopt entrepreneurial orientation? An empirical examination in Vietnam
}

\author{
Quang-Huy Ngo ${ }^{a^{*}}$ \\ ${ }^{a}$ FPT University, Vietnam

\section{CH R O N I C L E} \\ Article history: \\ Received February 21, 2021 \\ Received in revised format May \\ 20, 2021 \\ Accepted June 32021 \\ Available online \\ June 32021 \\ Keywords: \\ Differentiating strategy \\ Entrepreneurial orientation \\ Organizational performance \\ Resource-based view SME \\ Vietnam
}

\begin{abstract}
A B S T R A C T
Prior studies suggest that differentiating strategy (DS) has an intervening impact on the relationship between entrepreneurial orientation (EO) and performance. However, they only examine the impacts based on each dimension of EO, provide a lack of theory underpinning why this strategy is the mediator, and focus on the manufacturing industry of an emerging market. Addressing these gaps, the purpose of this study draws from the contingency theory in strategic management to examine whether this strategy is the mediator in the context of Vietnam. Partial least square structural equation modeling used to assess the research model with data collected from 142 SMEs operating in Vietnam. The result indicates that DS fully has an intervening effect on the association between EO and SMEs' performance.
\end{abstract}

\section{Introduction}

In entrepreneurial literature, entrepreneurial orientation (EO) has been intensively examined. In theory, when organizations adopt EO, it is suggested that they can improve organizational performance. However, the results of prior studies indicate mixed findings (see Soares \& Perin, 2020). Therefore, this relationship is argued to be influenced by mediators (see Choi \& Williams, 2016, pp. 3-4). However, studies on intervening impacts are still scarce, and as such, limit the understanding of the causal mechanisms of this variable (Wales et al., 2013). Prior studies use strategic management literature to explain how strategic choices the mediator is. Notably, Lechner and Gudmundsson (2014) proposed a research model indicating that differentiating strategy (DS) is the mediator between the dimensions of this orientation and performance of small businesses located in Iceland. Similarly, Zehir et al. (2015) also indicated that DS intervenes the association between dimensions of EO and performance when using the data collected from medium and large businesses located in Turkey to examine the research model. Similarly, Shah and Ahmad (2019) tested the same research model indicating DS is the mediator when using data collected from 166 manufacturing SMEs located in Pakistan. However, this study addresses three gaps relating two mentioned studies. First, these two studies do not use any underlying theory to explain why differentiating is the mediator. However, in strategic management literature, the contingency theory posits that strategic fits between organizational characteristics and strategic choices allow organizational performance improvement (Donaldson, 2001). According to Venkatraman and Camillus (1984), one way to propose the strategic fits is to assess the analytical framework, which indicates that strategic choices mediate the link between organizational characteristics and its performance. As a result, it limits the generalization of the contingency theory used to predict strategic alignment. Second, although the EO is conceptualized as a multidimensional construct, these mentioned studies only examined the impact of DS on the link between each dimension and performance. It leads to the limitations relating to the method to seek to answer whether DS is the contingent factor of the link between EO and performance. Third, although Shah and Ahmad (2019) used data collected from manufacturing SMEs operating in an emerging country to indicate that DS is the mediator between EO and performance, this finding cannot be generalized to the service industry. Therefore, a question, which is whether the strategic alignment between EO and DS allows both service and * Corresponding author

E-mail address: huynq121@,fe.edu.vn (Q.-H. Ngo)

(C) 2021 Growing Science Ltd. All rights reserved. doi: $10.5267 /$ j.uscm.2021.6.003 
manufacturing SMEs to find performance implications, has remained silent. Addressing these gaps, the purpose of this study is to draw from the contingency theory to examine whether the link between EO and SMEs' performance is mediated by a DS. Data were collected from 142 SMEs located in Vietnam. The technique of partial least square structural equation modeling (PLS-SEM) was used. The findings indicate that DS has a full intervening effect on the link between EO and SMEs' performance.

This study sheds light on the literature by indicating three contributions as follows. The first contribution is that this study draws from the contingency to explain how and why DS is the mediator. In this regard, this study overcomes the limitations regarding the theory used to describe the research model. Second, prior studies are subject to the limitation relating to the assessment of the EO concept because they assess the association between the strategy, performance respectively and each dimension of EO. This study considers EO as a second-ordered construct. In this regard, this consideration allows the assessment of DS on the link between EO and performance. The third contribution is the generalization of the prior studies' findings into the contexts of service and manufacturing SMEs by showing that when these SMEs adopt EO, DS is required for them to find performance implications. This study was outlined as follows. The following section provides the theoretical background and develops the tested hypotheses. After that, the section on methodology was presented. Later, the result section was introduced. The fifth section is the discussion. The last section is to conclude, provide caveats and propose future research avenues.

\section{Theoretical background and hypothesis development}

\subsection{Theoretical background}

\section{Entrepreneurial orientation}

The concept of EO is defined as an organization's entrepreneurial styles, philosophy, and behavior (Cools \& den Broeck, 2007; Covin \& Slevin, 1988). Miller (1983) conceptualized this orientation as consisting of three dimensions: innovativeness, proactiveness, and risk-taking. The first dimension indicates the degree to which organizations engage in activities relating to creating and experimenting with the products/services through the capabilities improvement to gain technological leadership. The second dimension refers to tendencies, which drive organizations to act upon future-oriented opportunities rather than rely on current opportunities. The last dimension allows the organization to willingly act on challenges and risks, although they may be risky. Due to this conceptualization, this study considers EO to be the second-order construct, which consists of three mentioned dimensions.

\section{Differentiation strategy}

Porter (1980) proposed a generic framework of strategy, which indicates that organizations can find competitive advantages when selecting appropriate strategies. In this framework, DS is argued to provide differentiating advantages. This strategy allows the organizations to be different in the market by delivering the products/services, which customers perceive to be unique in the market (Islami et al., 2020). As a result, a meta-analysis analysis indicates the sustainability of performance thanks to this strategy (Banker et al., 2014).

\section{Resource-based view}

The resource-based view (Barney, 1991) states that organizations can find performance implications when they own a resource, which is rare and valuable (Wernerfelt, 1984). In this regard, organizational competitive advantage demands this resource to be difficult to imitate by competitors in the market (Dierickx \& Cool, 1989).

\section{Contingency theory}

The contingency theory proposes that there is no universal way to organize the organizations to induce performance. Performance implication requires that organizational characteristics be aligned with the internal and external environment. In strategic management, strategic choices are required to be aligned with organizational characteristics to foster high performance. According to Venkatraman and Camillus (1984), strategic alignment can be assessed by examining the intervening role of strategic choices. In this regard, this study proposes that DS intervenes the association between EO and SMEs' performance.

\subsection{Hypothesis development}

\section{The relationship between $E O$ and $S M E s^{\prime}$ performance}

EO is argued to be the intangible capability of organizations (Shirokova et al., 2016). This capability allows for a high degree of exploratory and exploitation of new business opportunities and to be difficult to imitate or substitute by competitors 
(Barney, 1991; Lonial \& Carter, 2015). Thus, based on the resource-based view, an organization can find performance implications thanks to the adoption of EO (Wiklund, 1999). Prior studies' results support this argument (Alvarez-Torres et al., 2019; Zhang, 2012). This study expects the same result of EO on SMEs' performance. The first hypothesis is proposed as follows.

$\mathbf{H}_{1}$ : EO positively relates to SMEs' performance.

\section{The relationship between $E O$ and the selection of $D S$}

EO may lead to the selection of DS because three dimensions of EO link to this strategy. First, innovativeness allows customers to perceive products/services to be unique in the market, which gains competitive advantages resulting from DS (Das \& Joshi, 2007; Hoonsopon \& Ruenrom, 2012). Second, proactiveness induces first-mover advantages (Lumpkin \& Dess, 1996) resulted from DS because it allows organizations to focus on the future demands of customers, and as such, satisfy these demands by delivering their products/services, which are ahead of their competitors (Rahman \& Bhattacharyya, 2003). Third, risk-taking activities are crucial to gain differentiating advantages resulting from DS because the delivery of unique products/services require organizations to willingly accept a high degree of uncertainty (Galbreath et al., 2020). Zehir et al. (2015) and Lechner and Gudmundsson (2014) found that these three dimensions are positively linked to DS. In this regard, this study expects EO leads to the selection of DS of SMEs.

\section{$\mathbf{H}_{2}:$ EO positively relates to $D S$.}

The relationship between the selection of DS and the performance of SMES

Following a DS improves competitive advantages because it induces the uniqueness of the products/services in the market (Islami et al., 2020). Thanks to this strategy, the customers perceive that the products/services are superior compared to the available products/services in the market (Miller, 1988). Therefore, a meta-analysis study by Banker et al. (2014) indicated the sustainability of performance resulted from this strategy. In line with the mentioned study, this study expects the same effect: the selection of DS allows SMEs to gain superior performance. Notably, this study expects that SMEs selecting this strategy can gain competitive advantages because it allows their products/services to be unique in the market. Therefore, this strategy enhances customers' loyalty. It is argued that when loyalty is high, the customers are less likely to switch to other products/services, which results in less sensitivity in terms of price (Porter, 1985). In this regard, SMEs can gain more profit, which in turn leads to high performance. The third hypothesis is as shown below.

\section{$\mathbf{H}_{3}$ : DS positively relates to SMEs' performance.}

\section{The effect of the strategic alignment between EO and DS on SMEs' performance}

According to the contingency theory, the strategic alignment between organizational characteristics and choices allows superior performance. Strategic alignment can be varied, and each alignment can be assessed based on the analytical framework. (Venkatraman \& Camillus, 1984) propose that when strategic choices are the mediator between organizational characteristics and performance, strategic alignment is established. As a result, this study expects the strategic alignment between EO and DS allows SMEs to gain superior performance. Therefore, this study proposes the intervening role of DS in the association. The last hypothesis is as shown below.

\section{H4: DS mediates the relationship between EO and SMEs' performance.}

\section{Method}

\subsection{Sampling}

An email list containing 2.000 SMEs operating in Vietnam was obtained from a private seller to use for data collection. This study uses this method because there is no available information relating to the main variables in this study. The survey method allows the measurement of the main latent variables. An email was sent to all the email addresses. There are 254 emails, which failed to reach the destination. After a month and a half, a reminder was sent to these addresses. After two months, there are about 148 observations. The data cleaning process was applied. Six observations were removed due to most missing values (e.g., more than $80 \%$ ). In total, 142 observations were used in this study. Fig. 1 shows the SMEs' characteristics. There are 69 SMEs operating in the manufacturing industry and 73 SMEs operating in the services industry. The number of employees is varied between 10-200 as shown in Fig. 1. The rest of SMEs' characteristics is indicated in Fig. 1. 


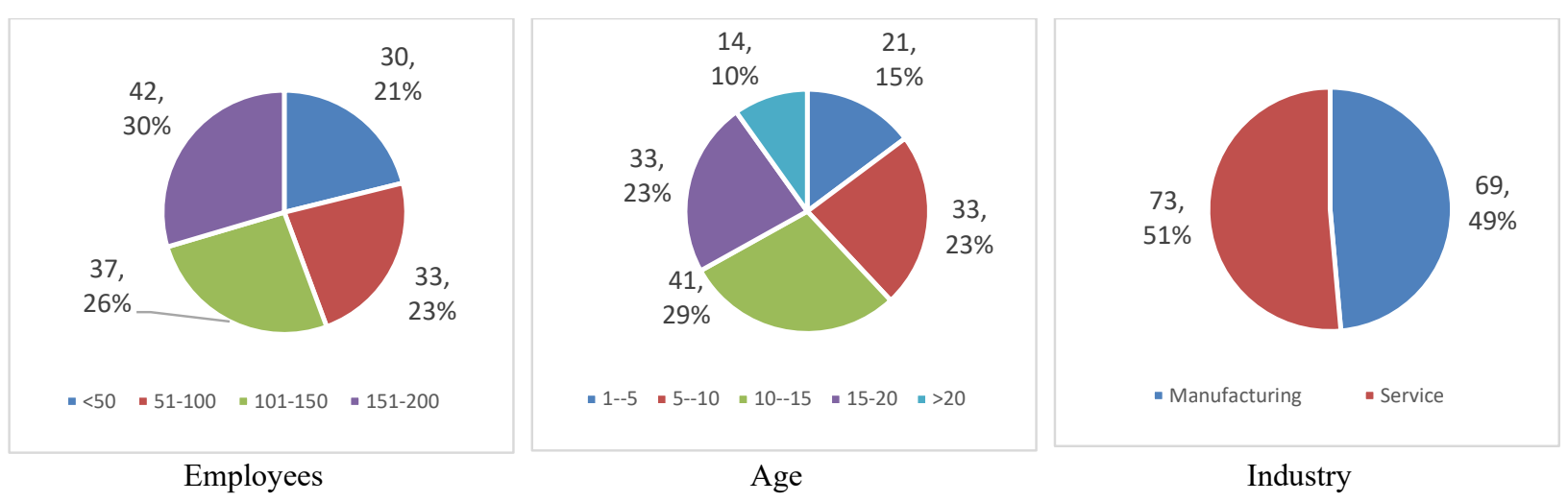

Fig. 1. Personal characteristics of the participants

\subsection{Measures}

All measures were adapted from prior research. The first measure (EO) was adapted from Eggers et al. (2013). In this instrument, there are three different instruments: innovativeness (IN), proactiveness (PR), and risk-taking (RT). Second, like Anwar and Shah (2021), an instrument from Kaya (2015) was used to measure the degree to which SMEs follow DS (DIF). Third, Prieto and Revilla (2006) provided an instrument to measure the performance relating to both financial and nonfinancial aspects. Therefore, this study relies on this instrument to measure the overall performance of SMEs (OP) because it is consistent with Rehman and Anwar (2019), who assessed the performance of SMEs. A 7-point-Likert scale was applied to all measures. The first and second asked the degree to which respondents agree on the proposed statement. The last instrument asks them to rate the performance of their SMEs relating to ten aspects of financial and non-financial performance.

\subsection{Analyzing techniques}

Hair et al. (2012) provided a detailed analysis about the use of PLS-SEM in strategic management literature. Thus, this study relies on this technique to examine. Besides, one benefit is that it allows the estimation of mediating impact (see Sarstedt et al., 2020). A two-stage approach was used to assess. More specifically, it consists of assessing measurement and structural model (Sarstedt \& Cheah, 2019). This study relies on SmartPLS 3.2.8 to analyze both measurement and structural models.

\subsection{Common method bias}

This study assessed the common method bias because this study collects data in the same survey. A Harman's single factor test was performed. To do this, a principal component analysis with no rotation was evaluated by using SPSS 20 . In this test, if the result indicates the first factor accounts for more than $50 \%$ of total variance, there is a concern of common method bias (Podsakoff \& Organ, 1986). The result from the test indicates that the first factor is only responsible for $46.692 \%$ of total variance. In this regard, common method bias poses not much concern on this study.

\section{Results}

\subsection{Measurement model}

This assessment is crucial to evaluate indicator loadings, internal consistency, convergent, and discriminant validity.

Table 1 shows that the indicator loadings are higher than the 0.708 threshold value (Hair et al., 2019) except OPER_6. This item was removed, and the results indicate that the first criteria are satisfied. Internal consistency reliability was assessed by using critical ratio and Cronbach's Alpha. These values are required to be higher than the 0.7 (Hair et al., 2019). Table 2 shows that this reliability is established. Convergent validity was examined by using average variance extracted (AVE). The values higher than 0.5 suggest the sufficient requirement (Hair et al., 2019). Table 2 shows that these values of all the constructs are higher than 0.5 , leading to the establishment of this validity. Discriminant validity is assessed by indicating the HeterotraitMonotrait (HTMT) ratio of correlations between constructs to be lower than 0.85 (Henseler et al., 2015). It is also noted that in this table, there is no evaluation of the HTMT ratio between EO and IN, PR, RT, respectively, because EO is the secondorder construct of these three variables. Table 3 shows the establishment of these criteria. 
Table 1

Loadings, Cronbach's alpha, Composite reliability, and AVE

\begin{tabular}{|c|c|c|c|c|c|c|}
\hline First-order & Second-order & Indicators & Loadings & Cronbach's alpha & Composite reliability & AVE \\
\hline \multirow{5}{*}{ Innovativeness } & & IN_1 & 0.904 & \multirow{5}{*}{0.934} & \multirow{5}{*}{0.95} & \multirow{5}{*}{0.791} \\
\hline & & IN_2 & 0.893 & & & \\
\hline & & IN_3 & 0.858 & & & \\
\hline & & IN_4 & 0.905 & & & \\
\hline & & IN_5 & 0.886 & & & \\
\hline \multirow{5}{*}{ Proactiveness } & & PR_1 & 0.870 & \multirow{5}{*}{0.929} & \multirow{5}{*}{0.947} & \multirow{5}{*}{0.780} \\
\hline & & PR_2 & 0.893 & & & \\
\hline & & PR_3 & 0.875 & & & \\
\hline & & PR_ 4 & 0.899 & & & \\
\hline & & PR $\_5$ & 0.877 & & & \\
\hline \multirow{7}{*}{ Risk-taking } & & RT_1 & 0.908 & \multirow{4}{*}{0.927} & \multirow{4}{*}{0.948} & \multirow{4}{*}{0.820} \\
\hline & & $\mathrm{RT} \_2$ & 0.912 & & & \\
\hline & & RT_3 & 0.905 & & & \\
\hline & & RT 4 & 0.896 & & & \\
\hline & \multirow{3}{*}{$\begin{array}{l}\text { Entrepreneurial } \\
\text { orientation }\end{array}$} & $\mathrm{IN}$ & 0.840 & \multirow{3}{*}{0.788} & \multirow{3}{*}{0.876} & \multirow{3}{*}{0.702} \\
\hline & & PR & 0.814 & & & \\
\hline & & RT & 0.858 & & & \\
\hline \multirow{5}{*}{$\begin{array}{l}\text { Differentiation } \\
\text { strategy }\end{array}$} & & DIF_1 & 0.853 & \multirow{5}{*}{0.918} & \multirow{5}{*}{0.938} & \multirow{5}{*}{0.753} \\
\hline & & DIF_2 & 0.888 & & & \\
\hline & & DIF_3 & 0.886 & & & \\
\hline & & DIF 4 & 0.856 & & & \\
\hline & & DIF 5 & 0.855 & & & \\
\hline \multirow{10}{*}{$\begin{array}{c}\text { Overall } \\
\text { performance }\end{array}$} & & OPER_1 & 0.825 & \multirow{10}{*}{0.945} & \multirow{10}{*}{0.953} & \multirow{10}{*}{0.695} \\
\hline & & OPER_10 & 0.857 & & & \\
\hline & & OPER_2 & 0.836 & & & \\
\hline & & OPER 3 & 0.830 & & & \\
\hline & & OPER_4 & 0.834 & & & \\
\hline & & OPER_5 & 0.847 & & & \\
\hline & & OPER_6 & 0.698 & & & \\
\hline & & OPER_7 & 0.840 & & & \\
\hline & & OPER_8 & 0.839 & & & \\
\hline & & OPER 9 & 0.761 & & & \\
\hline
\end{tabular}

Table 2

Heterotrait-Monotrait ratio

\begin{tabular}{lccccc}
\hline & DIF & EO & IN & OP & PR \\
\hline DIF & & & & & \\
EO & 0.761 & - & & & \\
IN & 0.611 & 0.521 & 0.382 & 0.447 & 0.562 \\
OP & 0.731 & - & 0.562 & 0.496 & 0.653 \\
PR & 0.642 & - & 0.560 & \\
RT & 0.672 & &
\end{tabular}

\subsection{Structural model}

The structural model was assessed using a bootstrapping procedure of 5.000 replacements. Before evaluating the results of the hypotheses tested, it is required to examine the collinearity, the model's explanatory power, and predictive accuracy (Hair et al., 2019). The first issue was examined by using VIFs. This value is necessarily lower than the threshold value of 3 (Hair et al., 2019). The model's explanatory power requires $R^{2}$ to be higher than 0.25 (Hair et al., 2019). The predictive accuracy demands the $Q^{2}$ value to be higher than zero (Hair et al., 2019). According to Table 4, these values are over the recommended value, and in turn, the requirements are all met.

Table 3

$R^{2}, Q^{2}$, and VIF of latent variables

\begin{tabular}{rccccc}
\hline & $R^{2}$ & $Q^{2}$ & & VIF & DO \\
\cline { 3 - 5 } & & 0.378 & DIF & 2.025 \\
DIF & 0.506 & & 1.000 & 2.025 \\
EO & & 0.306 & & & \\
\hline
\end{tabular}

Table 4 shows that all hypothesized paths are significant except the first hypothesis. More specifically, EO is not significantly related to SMEs performance is insignificant $(\beta=0.178, p=0.045)$. It leads to the rejection of the first hypothesis. The relationship between this orientation and DS is positively associated $(\beta=0.178, p=0.045)$. The second hypothesis is supported. 
The link between this strategy and the performance of SMEs is also positively correlated $(\beta=0.178, p=0.045)$. The third hypothesis is also supported.

Table 4

Relationship between latent variables

\begin{tabular}{llccrr}
\hline Hypothesis & Path & Beta & $t$-value & $p$-values & Confident interval \\
\hline H1 & EO $\rightarrow$ OP & 0.002 & 0.020 & 0.984 & 0.000 \\
H2 & EO $\rightarrow$ DIF & 0.711 & 13.24 & 0.000 & {$[-0.163,0.171]$} \\
H3 & DIF $\rightarrow$ OP & 0.673 & 8.429 & $0.583,0.800]$ \\
H4 & EO $\rightarrow$ DIF $\rightarrow$ OP & 0.479 & 7.744 & 0.000 & {$[0.481,0.803]$} \\
\hline
\end{tabular}

This study relies on the procedure of Zhao et al. (2010) to test the mediator. The previous paragraph shows that the relationship between independent, latent dependent variable and mediator is established. It leads to examining the significant degree of the mediating test and the confidence intervals of this test. Table 5 shows the support for the last hypothesis. It is concluded that the strategic alignment between these two variables allows SMEs located in Vietnam find the performance implication.

\section{Discussion}

First, the result indicates EO has no direct relationship with SMEs' performance. This finding can be interpreted as that when SMEs located in Vietnam adopt this orientation cannot directly find performance implications. One proper explanation is that although the EO is an organizational capability, it is valuable and rare in the market and difficult to imitate. According to the VRIO framework, an analytical approach of the resource-based view (Barney, 2014), this capability requires the organization to be well-organized to sustain its competitive advantages. This argument is like Chatzoglou et al. (2018), who argued that organizational capabilities and resources need to satisfy four criteria (e.g., value, rare, inimitable, and well-organized) to sustain performance. As a result, it leads to the insignificant effects of EO on SMEs' performance. This result shares the same similarity with Alegre and Chiva (2013), who found the insignificant indirect relationship between EO and firm performance when including two variables as innovation performance and organizational learning capabilities in the model.

Second, the finding shows the positive relationship between EO and DS. It can be interpreted as that SMEs adopting EO select a DS as the competitive strategy. Adopting this orientation allows SMEs to gain innovativeness, be proactive, and exert risktaking behavior (Miller, 1983). Three characteristics allow SMEs to deliver products/services, which are unique in the market. Mainly, the first characteristic drives SMEs to engage in creative and experiential activities to gain technological leadership, which leads to the differentiating advantages (Das \& Joshi, 2007; Hoonsopon \& Ruenrom, 2012). The second characteristics induce SMEs to act upon future-oriented opportunities. In this regard, they emphasize customers' needs and deliver products/services, which are different in the market, to satisfy those needs. Thus, these characteristics induce first-mover advantages (Lumpkin \& Dess, 1996) resulting from DS (Rahman \& Bhattacharyya, 2003). The last characteristic is crucial to SMEs to gain such uniqueness because to provide unique products/services, which is the core characteristic of DS, SMEs must willingly act challenges and risk, resulting in high uncertainty (Galbreath et al., 2020). In summary, SMEs adopting EO select this strategy to find competitive advantages. This finding is consistent with (Hernández-Perlines et al., 2016), who indicated that international EO, an extension of EO, induces the selection of competitive strategy.

Third, the result demonstrates the positive association between DS and the performance of SMEs. In this regard, this result can be interpreted as that SMEs selecting DS gain superior performance. One proper explanation is as follows. This strategy allows the customer to perceive the products/services to be superior and unique in the market (Islami et al., 2020; Miller, 1988). This strategy was indicated to improve the customers' loyalty (Souitaris \& Balabanis, 2007). Because this loyalty is less sensitive to price changes, selecting this strategy allows SMEs to charge premium prices or sell more products/services at the same price to their customers, leading to higher profit (Porter, 1985). This finding is consistent with Banker et al. (2014), who indicated the sustainable performance of this strategy.

Fourth, the finding indicates that the link between EO and SMEs' performance is mediated by DS. It is implied that the alignment between EO and DS is required to foster the superior performance of SMEs. It can be explained by the VRIO framework (Barney, 2014). As indicated earlier, although the EO is valuable to SMEs, rare in the industry, and difficult to imitate by competitors in the market, this capability needs to be well-organized. In this regard, the alignment between EO and DS can be referred to like the organizations sustaining competitive advantages, resulting in high performance. This finding is like (Hernández-Perlines et al., 2016) in the extent to which that study demonstrated that competitive strategy is the mediator of the association between international EO and international performance. In comparison to prior studies examining the intervening effect of DS on the link between EO and performance. This study's results are consistent with both Zehir et al. (2015) and Shah and Ahmad (2019). In this regard, this study extends our knowledge by showing that the strategic alignment between DS and EO is required for both service and manufacturing SMEs operating find the performance implication. 


\section{Conclusion, limitations, and directions for future research}

This study's aim is to unravel the impact of strategic alignment between market orientation and DS on SMEs' performance implication. The results indicate this alignment, which represents the intervening impact of the strategy on the link between EO and performance, allows SMEs to find performance implications. In this regard, this study contributes to the literature twofold. The first contribution is to use the second-order constructs of EO to assess the research model. The second contribution is to generalize prior studies' results to SMEs located in an emerging country. Although this study provides some valuable contributions, it should be cautious that the interpretation of the results should consider the following caveats. First, data was collected in Vietnam. As a result, the generalization to other countries should be cautious. Second, data was collected at a point in time. It leads to the limitation of causal inference. Despite some limitations, this study reveals an avenue for future studies. First, future studies should use longitudinal data to overcome the limitation of causal inference. Second, this study only considers the internal characteristics of SMEs (e.g., EO and DS). Future studies should include variables measuring the external environment because the contingency theory posits that the alignment between organizational characteristics and the external environment improves performance. Lastly, because this study and Shah and Ahmad (2019) both focus on the Asia context, future studies should replicate this research model using data collected in other contexts.

\section{References}

Alegre, J., \& Chiva, R. (2013). Linking entrepreneurial orientation and firm performance: The role of organizational learning capability and innovation performance. Journal of Small Business Management, 51(4), 491-507.

Alvarez-Torres, F. J., Lopez-Torres, G. C., \& Schiuma, G. (2019). Linking entrepreneurial orientation to SMEs' performance. Management Decision.

Anwar, M., \& Shah, S. Z. (2021). Entrepreneurial orientation and generic competitive strategies for emerging SMEs: Financial and nonfinancial performance perspective. Journal of Public Affairs, 21(1), e2125.

Banker, R. D., Mashruwala, R., \& Tripathy, A. (2014). Does a differentiation strategy lead to more sustainable financial performance than a cost leadership strategy? Management Decision, 52(5), 872-896.

Barney, J. (1991). Firm resources and sustained competitive advantage. Journal of Management, 17(1), 99-120.

Barney, J. B. (2014). Gaining and sustaining competitive advantage: Pearson higher ed.

Chatzoglou, P., Chatzoudes, D., Sarigiannidis, L., \& Theriou, G. (2018). The role of firm-specific factors in the strategyperformance relationship: Revisiting the resource-based view of the firm and the VRIO framework. Management Research Review, 41(1), 46-73.

Choi, S. B., \& Williams, C. (2016). Entrepreneurial orientation and performance: mediating effects of technology and marketing action across industry types. Industry and Innovation, 23(8), 673-693.

Cools, E., \& den Broeck, V. (2007). The hunt for the Heffalump continues: can trait and cognitive characteristics predict entrepreneurial orientation? Journal of Small Business Strategy, 18(2), 23-42.

Covin, J. G., \& Slevin, D. P. (1988). The influence of organization structure on the utility of an entrepreneurial top management style. Journal of Management Studies, 25(3), 217-234.

Das, S. R., \& Joshi, M. P. (2007). Process innovativeness in technology services organizations: Roles of differentiation strategy, operational autonomy and risk-taking propensity. Journal of Operations Management, 25(3), 643-660.

Dierickx, I., \& Cool, K. (1989). Asset stock accumulation and sustainability of competitive advantage. Management science, 35(12), 1504-1511.

Donaldson, L. (2001). The contingency theory of organizations: Sage.

Eggers, F., Kraus, S., Hughes, M., Laraway, S., \& Snycerski, S. (2013). Implications of customer and entrepreneurial orientations for SME growth. Management Decision, 51(3), 524-546.

Galbreath, J., Lucianetti, L., Thomas, B., \& Tisch, D. (2020). Entrepreneurial orientation and firm performance in Italian firms. International Journal of Entrepreneurial Behavior \& Research, 26(4), 629-646.

Hair, J. F., Risher, J. J., Sarstedt, M., \& Ringle, C. M. (2019). When to use and how to report the results of PLS-SEM. European Business Review, 31(1), 2-24.

Hair, J. F., Sarstedt, M., Pieper, T. M., \& Ringle, C. M. (2012). The use of partial least squares structural equation modeling in strategic management research: a review of past practices and recommendations for future applications. Long Range Planning, 45(5-6), 320-340.

Henseler, J., Ringle, C. M., \& Sarstedt, M. (2015). A new criterion for assessing discriminant validity in variance-based structural equation modeling. Journal of the Academy of Marketing Science, 43(1), 115-135.

Hernández-Perlines, F., Moreno-García, J., \& Yañez-Araque, B. (2016). The mediating role of competitive strategy in international entrepreneurial orientation. Journal of Business Research, 69(11), 5383-5389.

Hoonsopon, D., \& Ruenrom, G. (2012). The impact of organizational capabilities on the development of radical and incremental product innovation and product innovation performance. Journal of Managerial Issues, 24(3), $250-276$.

Islami, X., Latkovikj, M. T., Drakulevski, L., \& Popovska, M. B. (2020). Does differentiation strategy model matter? Designation of organizational performance using differentiation strategy instruments-an empirical analysis. Business: Theory and Practice, 21(1), 158-177. 
Kaya, N. (2015). Corporate entrepreneurship, generic competitive strategies, and firm performance in small and mediumsized enterprises. Procedia-Social and Behavioral Sciences, 207, 662-668.

Lechner, C., \& Gudmundsson, S. V. (2014). Entrepreneurial orientation, firm strategy and small firm performance. International Small Business Journal, 32(1), 36-60.

Lonial, S. C., \& Carter, R. E. (2015). The impact of organizational orientations on medium and small firm performance: A resource-based perspective. Journal of Small Business Management, 53(1), 94-113.

Lumpkin, G. T., \& Dess, G. G. (1996). Clarifying the entrepreneurial orientation construct and linking it to performance. Academy of Management Review, 21(1), 135-172.

Miller, D. (1983). The correlates of entrepreneurship in three types of firms. Management Science, 29(7), 770-791.

Miller, D. (1988). Relating Porter's business strategies to environment and structure: Analysis and performance implications. Academy of Management Journal, 31(2), 280-308.

Podsakoff, P. M., \& Organ, D. W. (1986). Self-reports in organizational research: Problems and prospects. Journal of Management, 12(4), 531-544.

Porter, M. (1980). Competitive strategy: Techniques for analyzing industries and competitors. New York: Free Press.

Porter, M. (1985). Competitive Advantage: Creating and Sustaining Superior Performance. New York: The Free Press.

Prieto, I. M., \& Revilla, E. (2006). Learning capability and business performance: a non-financial and financial assessment. The Learning Organization, 13(2), 166-185.

Rahman, Z., \& Bhattacharyya, S. (2003). Sources of first mover advantages in emerging markets-an Indian perspective. European Business Review, 15(6), 359-369.

Rehman, A. U., \& Anwar, M. (2019). Mediating role of enterprise risk management practices between business strategy and SME performance. Small Enterprise Research, 26(2), 207-227.

Sarstedt, M., \& Cheah, J.-H. (2019). Partial least squares structural equation modeling using SmartPLS: a software review. Journal of Marketing Analytics, 7, 96-202.

Sarstedt, M., Hair Jr, J. F., Nitzl, C., Ringle, C. M., \& Howard, M. C. (2020). Beyond a tandem analysis of SEM and PROCESS: Use of PLS-SEM for mediation analyses! International Journal of Market Research, 62(3), 288-299.

Shah, S. Z. A., \& Ahmad, M. (2019). Entrepreneurial orientation and performance of small and medium-sized enterprises. Competitiveness Review: An International Business Journal, 29(5), 551-572.

Shirokova, G., Bogatyreva, K., Beliaeva, T., \& Puffer, S. (2016). Entrepreneurial orientation and firm performance in different environmental settings. Journal of Small Business and Enterprise Development, 23(3), 703-727.

Soares, M. d. C., \& Perin, M. G. (2020). Entrepreneurial orientation and firm performance: an updated meta-analysis. RAUSP Management Journal, 55(2), 143-159.

Souitaris, V., \& Balabanis, G. (2007). Tailoring online retail strategies to increase customer satisfaction and loyalty. Long Range Planning, 40(2), 244-261.

Venkatraman, N., \& Camillus, J. C. (1984). Exploring the concept of "fit" in strategic management. Academy of Management Review, 9(3), 513-525.

Wales, W. J., Gupta, V. K., \& Mousa, F.-T. (2013). Empirical research on entrepreneurial orientation: An assessment and suggestions for future research. International Small Business Journal, 31(4), 357-383.

Wernerfelt, B. (1984). A resource-based view of the firm. Strategic Management Journal, 5(2), 171-180.

Wiklund, J. (1999). The sustainability of the entrepreneurial orientation-performance relationship. Entrepreneurship Theory and Practice, 24(1), 37-48.

Zehir, C., Can, E., \& Karaboga, T. (2015). Linking entrepreneurial orientation to firm performance: the role of differentiation strategy and innovation performance. Procedia-Social and Behavioral Sciences, 210, 358-367.

Zhang, Y. (2012). The effect of entrepreneurial orientation on business performance. Journal of Chinese Entrepreneurship, $4(2), 132-142$

Zhao, X., Lynch Jr, J. G., \& Chen, Q. (2010). Reconsidering Baron and Kenny: Myths and truths about mediation analysis. Journal of Consumer Research, 37(2), 197-206.

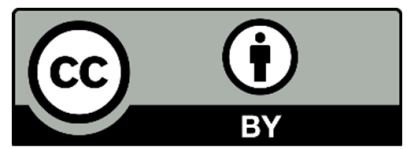

(C) 2021 by the authors; licensee Growing Science, Canada. This is an open access article distributed under the terms and conditions of the Creative Commons Attribution (CCBY) license (http://creativecommons.org/licenses/by/4.0/). 